\title{
Natural triploidy in Leporinus cf. elongatus bearing sex chromosomes
}

\author{
Wagner Franco Molina ${ }^{1}$, Vladimir Pavan Margarido ${ }^{2}$ and Pedro Manoel Galetti $\mathrm{Jr}^{3}$ \\ ${ }^{1}$ Departamento de Biologia Celular e Genética, Universidade Federal do Rio Grande do Norte, \\ Natal, RN, Brazil. \\ ${ }^{2}$ Centro de Ciências Biológicas e da Saúde, Universidade Estadual do Oeste do Paraná, Cascavel, \\ PR, Brazil. \\ ${ }^{3}$ Departamento de Genética e Evolução, Universidade Federal de São Carlos, São Carlos, SP, Brazil.
}

\begin{abstract}
Although several cases of natural triploidy in fish have already been described, spontaneous polyploidy in species with differentiated sex chromosomes are rare. We report the occurrence of a triploid fish $(3 n=81)$ Leporinus cf. elongatus, a species characterized by a highly differentiated ZZ/ZW sex chromosome system, from the São Francisco river. The occurrence of a ZZZ triploid adult indicates the viability of this chromosome constitution in this fish.
\end{abstract}

Key words: polyploidy, triploid fish, ZW chromosomes, sex chromosomes, Anostomidae.

Received: May 11, 2006; Accepted: November 23, 2006.

The family Anostomidae is composed of 12 genera, constituting a group relatively rich in species, distributed from South to Central America (Garavello, 1979). Eight species from this group, all from the genus Leporinus, exhibit a ZZ/ZW sex chromosome system with marked structural modifications between the sex chromosomes (Galetti et al., 1995; Venere et al., 2004; Molina and Galetti, 2006). The ZW chromosomes of these species point a monophyletic origin, apparently differentiated through processes of heterochromatinization (Galetti and Foresti, 1986; 1987). Leporinus is one of the more complexes groups among Characiformes and the largest in number of species, with 87 already described. Several attempts to subdivide it into additional genera and subgenera have failed (Garavello and Britski, 2003).

A diploid number of $2 \mathrm{n}=54$ is common among Leporinus species (Galetti et al., 1995) and no chromosome number variation has been reported in this genus thus far, despite of several reports of natural triploidy in different neotropical fish families (Characidae, Morelli et al., 1983; Fauaz et al., 1994; Centofante et al. 2001; Sternopygidae, Almeida-Toledo et al., 1985; Curimatidae, Venere and Galetti, 1985; Erythrinidae, Giuliano-Caetano and Bertollo, 1990; Thricomycteridae, Borin et al., 2002).

This study reports a case of spontaneous natural triploidy in Leporinus cf. elongatus with a highly differentiated ZZ/ZW sex chromosome system.

Send correspondence to Wagner Franco Molina. Departamento de Biologia Celular e Genética, Universidade Federal do Rio Grande do Norte, Campus Universitário, 59078-970 Natal, RN, Brazil. E-mail: molinawf@yahoo.com.br.
A total of 28 specimens of Leporinus cf. elongatus (12 males and 16 females) collected in the São Francisco river (Três Marias municipality; Brazil) were cytogenetically analyzed through the air-drying technique (Bertollo et al., 1978; Gold et al., 1990). the chromosome preparations were submitted to Ag-NOR (Howell and Black, 1980) and mithramycin staining (Schweizer, 1980).

Our results confirmed the previously reported $2 \mathrm{n}=54$ with a highly differentiated ZZ/ZW sex chromosome system, characterized by a large subtelocentric W chromosome and a submetacentric Z (Molina et al., 1998).

A young triploid male with $2 n=3 x=81$ and presenting three copies of the $\mathrm{Z}$ chromosome was detected (Figure $1 \mathrm{a}, \mathrm{b})$. A previously reported conspicuous mithramycin positive heterochromatic block on the long arm of the $\mathrm{Z}$ chromosomes (Molina et al., 1998) was evident in the three $\mathrm{Z}$ chromosomes of the triploid complement (Figure 1c). No morphological differences were observed between the triploid and the diploid specimens.

The nucleolus organizer regions (NORs) were located near the telomere of the long arm of a large submetacentric chromosome in the diploid individuals (Figure 1d). Although good quality metaphases were not obtained for Ag-staining in the triploid specimen, while the interphase nuclei of diploid individuals has showed a maximum of two Ag-stained nucleoli in the triploid three nucleoli were detected (Figure 1e), indicating that these three constitutive NOR sites can be active in the triploid. Similar results were also observed in Trichomycterus davisi (Borin et al., 2002). 
Polyploidy is believed to be an important mechanism in the chromosome evolution in some fish groups, such as Catostomidae and Salmonidae (reviewed in Comber and Smith, 2004) or in the neotropical Siluriformes, as Corydoras, Aspidoras and Brochis (Oliveira et al., 1993). Therefore, the polyploidy is particularly propitious to the evolutionary failure in species with differentiated sex chromosomes, likely due to a gene imbalance (Müller, 1925; Svartman et al., 2005). On the other hand, random natural triploidy appears more frequent in fish and it is mostly correlated to exposition to drastic temperature changes or other environmental conditions (Venere and Galetti, 1985), once the fecundation most of the time is external. However, natural triploidy in fish species with differentiated sex chromosomes is very rare.

In a set of 27 individuals of Characidium gomesi, which presents a ZZ/ZW system, Centofante et al. (2001) reported the occurrence of a triploid female. This triploid exhibited one $\mathrm{W}$ and two $\mathrm{Z}$ chromosomes, suggesting that it resulted from the fertilization of a normal (haploid) ovule by a non-reduced spermatozoid ( $2 n$ ). The presence of three $\mathrm{Z}$ chromosomes in the triploid male herein studied prevented us from determining if the triploidy was originated by maternal or paternal non-segregation.

The occurrence of triploids in cytogenetic analyses with samples relatively small as in L. cf. elongatus from the São Francisco river suggests that polyploidy events should happen in a larger frequency than could be imagined. However, one of the limitations to the evolution through the polyploidy in vertebrates has been attributed to the presence of differentiated sex chromosomes (Svartman et al., 2005).

The presence of sex chromosomes does not seem to impair the triploid development in L. cf. elongatus and our a

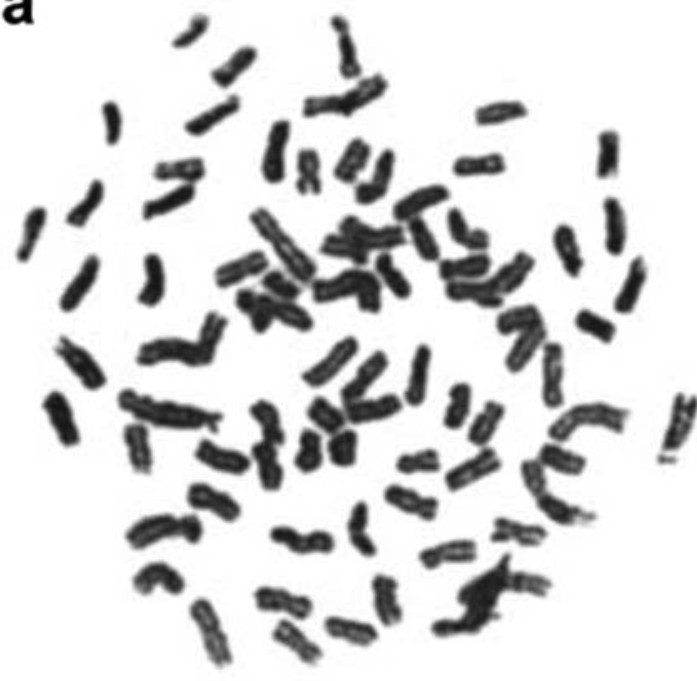

b
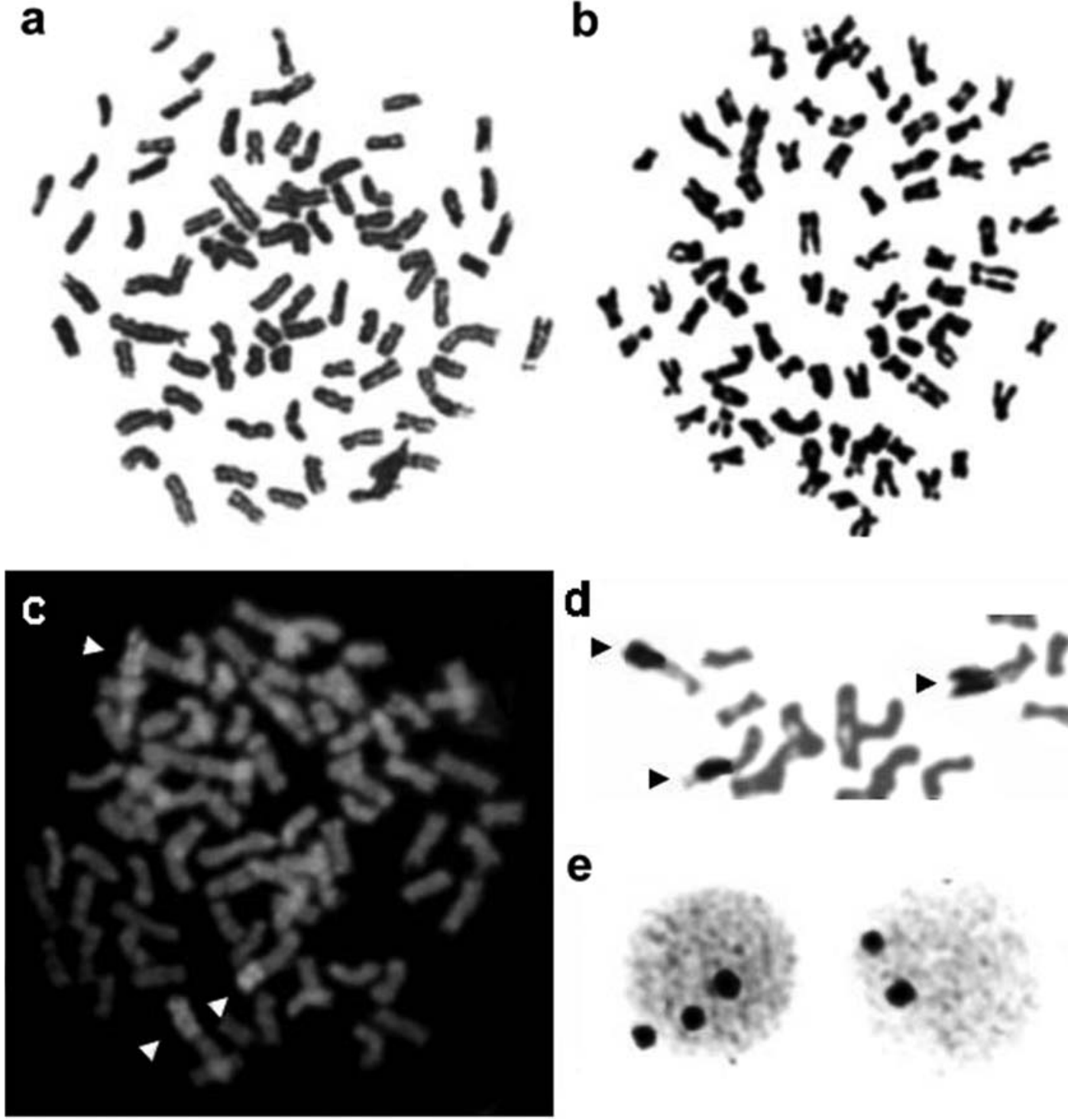

d

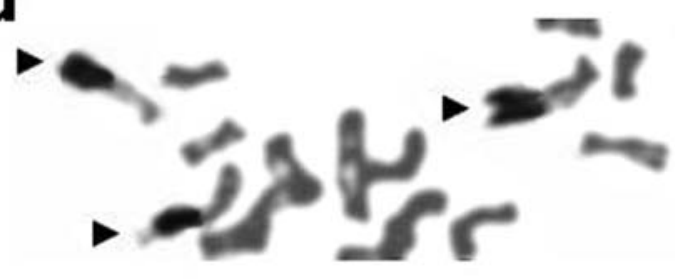

e
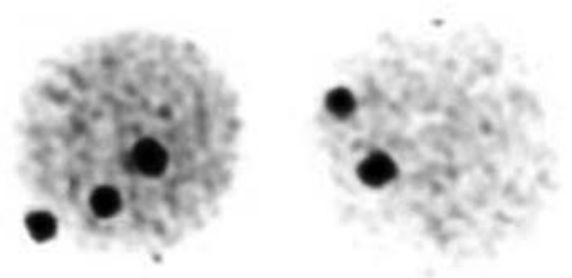

Figure 1 - (a-c) Metaphases of a triploid male L. cf. elongatus. (a-b) Giemsa staining. (c) Mithramycin staining. Arrows indicate the Z chromosomes. (d) Ag-stained partial diploid metaphase with two Ag-NOR bearing chromosomes. (e) Ag-stained nucleoli in the triploid specimen. 
findings may have direct implications on the genetic manipulation of this fish and of other species bearing differentiated sex chromosomes.

\section{Acknowledgements}

The authors thank Fundação Coordenação de Aperfeiçoamento de Pessoal de Nível Superior (CAPES) and Conselho Nacional de Desenvolvimento Científico e Tecnológico $(\mathrm{CNPq})$ for financial support.

\section{References}

Almeida Toledo LF, Foresti F and Toledo Filho SA (1985) Spontaneous triploidy and NOR activity in Eigenmannia sp. (Pisces, Sternopygidae) from the Amazon basin. Genetica 66:85-88.

Bertollo LAC, Takahashi CS and Moreira-Filho O (1978) Cytotaxonomic considerations on Hoplias lacerdae (Pisces, Erythrinidae). Rev Brasil Genet 1:103-120.

Borin LA, Martins-Santos IC and Oliveira C (2002) A natural triploid in Trichomycterus davisi (Siluriformes, Trichomycteridae): Mitotic and meiotic characterization by chromosome banding and synaptonemal complex analyses. Genetica 115:253-258.

Centofante L, Bertollo LAC and Moreira-Filho O (2001) Comparative cytogenetics among sympatric species of Characidium (Pisces, Characiformes). Diversity analysis with the description of a ZW sexual chromosome system and natural triploidy. Caryologia 54:253-260.

Comber SCL and Smith C (2004) Polyploidy in fishes: Patterns and processes. Biological Journal of the Linnean Society 82:431-442.

Fauaz G, Vicente VE and Moreira-Filho O (1994) Natural triploidy and B chromosomes in the neotropical fish genus Astyanax (Characidae). Brazil J Genet 17:157-163.

Galetti Jr PM and Foresti F (1986) Evolution of the ZZ/ZW system in Leporinus (Pisces, Anostomidae). Role of Constitutive heterochromatin. Cytogenet Cell Genet 43:43-46.

Galetti Jr PM and Foresti F (1987) Two new cases of ZZ/ZW heterogamety in Leporinus (Pisces, Anostomidae) and their relationships in the phylogeny of the group. Rev Brasil Genet 1:135-140.

Galetti Jr PM, Lima NRW and Venere PC (1995) A monophyletic ZW sex chromosome system in Leporinus (Anostomidae, Characiformes). Cytologia 60:375-382.
Garavello JC (1979) Revisão taxonômica do gênero Leporinus Spix, 1829 (Ostariophysi, Anostomidae). Doctoral Thesis. Universidade de São Paulo, São Paulo.

Garavello JC and Britski HA (2003) Family Anostomidae. In: Reis RE, Kullander SO and Ferraris Jr CJ (eds) Check List of the Freshwater Fishes of South and Central America. Edipucrs, Porto Alegre, pp 71-84.

Giuliano-Caetano L and Bertollo LAC (1990) Karyotypic variability in Hoplerythrinus unitaeniatus (Pisces, Characiformes, Erythrinidae). II. Occurrence of natural triploidy. Brazil J Genet 13:231-237.

Gold JR, LI C, Shipley NS and Powers PK (1990) Improved methods for working with fish chromosomes with a review of metaphase chromosome banding. J Fish Biol 37:563-575.

Howell WM and Black A (1980) Controlled silver staining of nucleolus organizer regions with a protective colloidal developer: A 1- step method. Experientia 36:1014-1015.

Molina WF, Schmid M and Galetti Jr PM (1998) Heterochromatin and sex chromosomes in the Neotropical fish genus Leporinus (Characiformes, Anostomidae). Cytobios 94:141-149.

Molina WF and Galetti Jr PM (2007) Early replication banding in Leporinus species (Osteichthyes, Characiformes) bearing differentiated sex chromosomes (ZW). Genetica 130:153160 .

Morelli S, Bertollo LAC and Moreira-Filho O (1983) Cytogenetic considerations on the genus Astyanax (Pisces, Characidae). II Ocurrence of natural triploidy. Caryologia 36:245-250.

Müller HJ (1925) Why polyploidy is rarer in animals than in plants. American Naturalist 59:346-353.

Oliveira C, Almeida-Toledo LF, Mori L and Toledo-Filho SA (1993) Cytogenetic and DNA content in six genera of the family Callichthyidae (Pisces, Siluriformes). Caryologia 46:171-188.

Schweizer D (1980) Simultaneous fluorescent staining of R bands and specific heterochromatic regions (DA-DAPI bands) in human chromosomes. Cytogenet Cell Genet 27:190-193.

Svartman M, Stone G and Stanyon R (2005) Molecular cytogenetics discards polyploidy in mammals. Genomics 85:425430.

Venere PC and Galetti Jr PM (1985) Natural triploidy and chromosome B in the fish Curimata modesta (Curimatidae, Characiformes). Rev Brasil Genet 7:681-687.

Venere PC, Ferreira IA, Cesar Martins C and Galetti Jr PM (2004) A novel ZZ/ZW sex chromosome system for the genus Leporinus (Pisces, Anostomidae, Characiformes). Genetica 121:75-80.

Associate Editor: Fausto Foresti 